\title{
Birdcage Neutron Coincidence Counter Manual
}

\author{
M.S. Krick \\ H.O. Menlove \\ A. Ramalho*
}

LA- $-10430-M$

$\$ 285017954$

\section{DISCLAIMER}

This report was prepared as an account of work sponsored by an agency of the United States Government. Neither the United States Government nor any agency thereof, nor any of their employees, makes any warranty, express or implied, or assumes any legal liability or responsibility for the accuracy, completeness, or usefulness of any information, apparatus, product, or process disclosed, or represents that its use would not infringe privately owned rights. Reference herein to any specific commercial product, process, or service by trade name, trademark, manufacturer, or otherwise does not necessarily constitute or imply its endorsement, recommendation, or favoring by the United States Government or any agency thereof. The views and opinions of authors expressed herein do not necessarily state or reflect those of the United States Government or any agency thereof. 


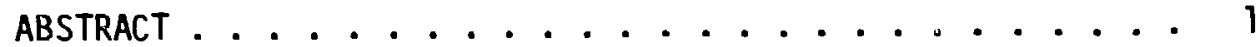

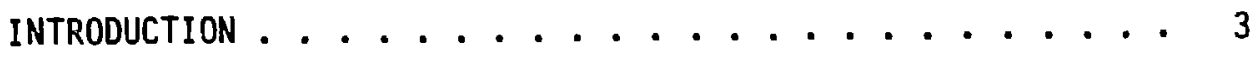

BIRDCAGE DESCRIPTION . . . . . . . . . . 5

Birdcage ...................... 5

Canister.............. . . 5

MEASUREMENT SYSTEM ...................... 6

Complete System . . . . . . . . . . . . 6

Detector Body . . . . . . . . . . . . 6

Design ............... . . 6

${ }^{3}$ He Counter Tubes and Cadmium ........ 7

Uniformity of Efficiency . . . . . . . . 7

${ }^{252}$ Cf Source Holder ............ 10

Detector Tubes .............. 10

High-Voltage Junction Box ............ 10

Coincidence Electronics Package . . . . . . . . . 11

Recommended Settings........... 12

${ }^{252}$ Cf Nomalization Source ........... 12

OPERATING CHARACTERISTICS .................. 14

Detection Efficiency ............ 14

Die-away Time ................ 14

Deadtime Coefficients ............ 14

Stability ............... 15

Angular Response ............. 15

Vertical Response.............. 15

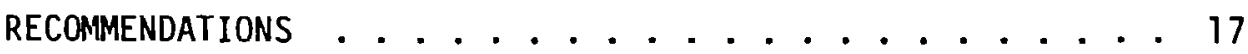

Birdcage Positioning ............. 17

Multiplication Correction ........... 17

REFERENCES .............................. 18 
BIRDCAGE NEUTRON COINCIDENCE COUNTER MANUAL

by

M. S. Krick, H. O. Menlove, and A. Ramalho

\begin{abstract}
A thermal neutron coincidence counter has been constructed for the assay of fast critical assembly fuel plates stored in biracages. Standard coinridence counting electronics are used. This manual describes the birdcage, the measurement system, and its performance characteristics.
\end{abstract}


The International Atomic Energy Agency (IAEA) needs the capability to conduct independent on-site verification of the plutonium content of fast critical assembly fuel plates that are stored in containers called birdcages. The IAEA should be able to assay the plutonium content of the birdcages without removing the fuel piates from the birdcages. To accomplish this verification a thermal neutron coincidence counter was custom designed and constructed at Los Alamos National Laboratory. The counter is called the Birdcage Neutron Coincidence Counter and is designated as BCNC by the IAEA.

This manual comprises four main sections:

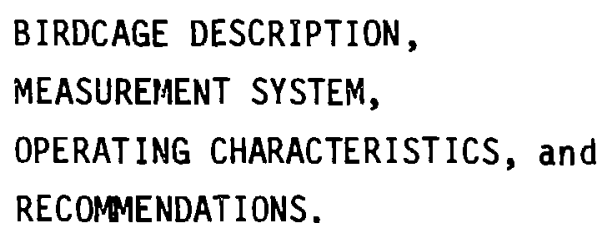

The manual provides technical information on the BCNC for the operations, technical services, development, and training sections of the IAEA. It is assumed that the reader is already familiar with thermal neutron coincidence counting. 


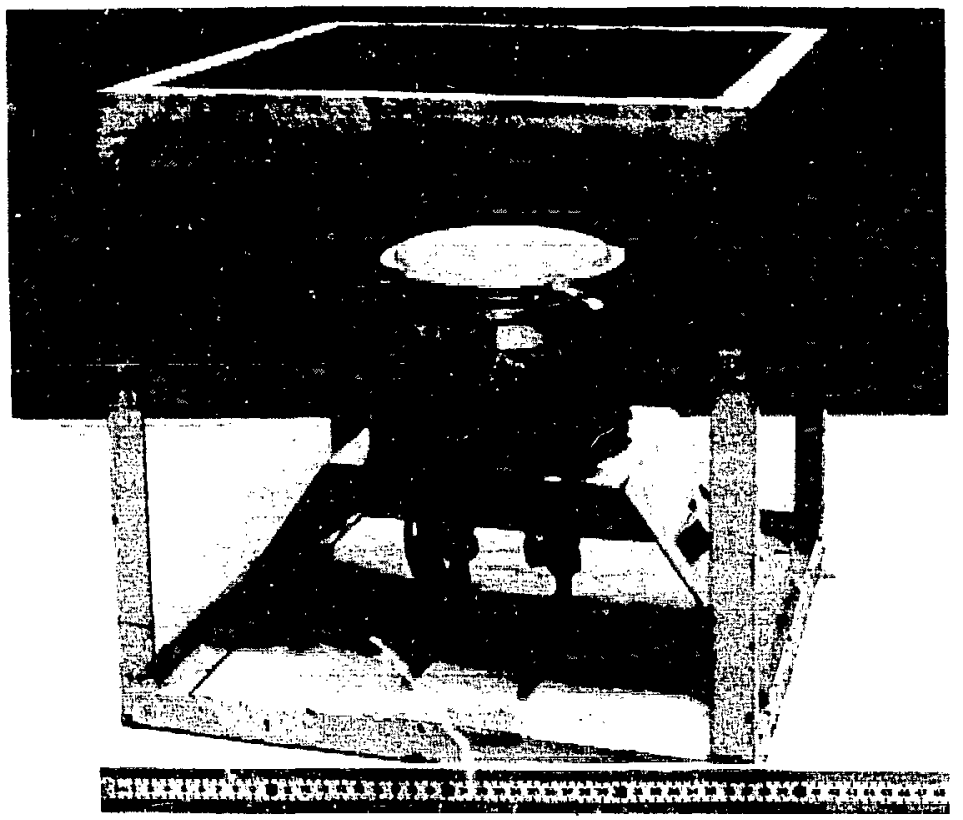

Fig. 1. The complete birdcage assembly, showing the fuel storage canister and support bracket.

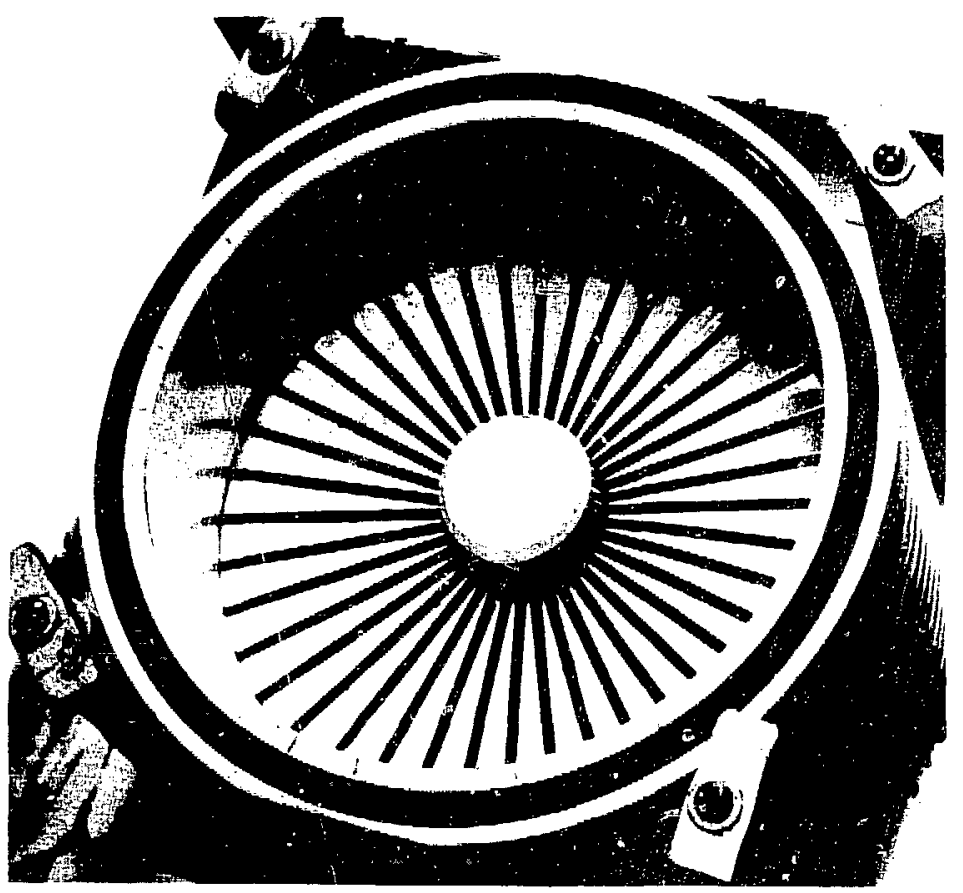

Fig. 2. The inside of a canister. The slotted cylindrical fuel plate holder is removable. 


\section{BIRDCAGE}

Canister
A birdcage is a storage container for fast critical assembly fuel plates. It comprises a cubic metal framework with a canister supported at its center that holds the fuel plates, as shown in Fig. 1. The birdcage is $40 \mathrm{~cm}$ on a side. This geometry assures nuclear criticality safety. The plumbing at the bottom of the birdcage allows for air circulation, evacuation, and sampling.

Figure 2 shows the inside of the canister. The slotted cylinder that holds the fuel plates is removable. Figure 3 shows two types of cylinders that hold fuel in the canister. Up to $2 \mathrm{~kg}$ of plutonium is stored in one canister. The clamps at the top of the canister are used to hold the lid on the 0 ring to form a vacuum seal.

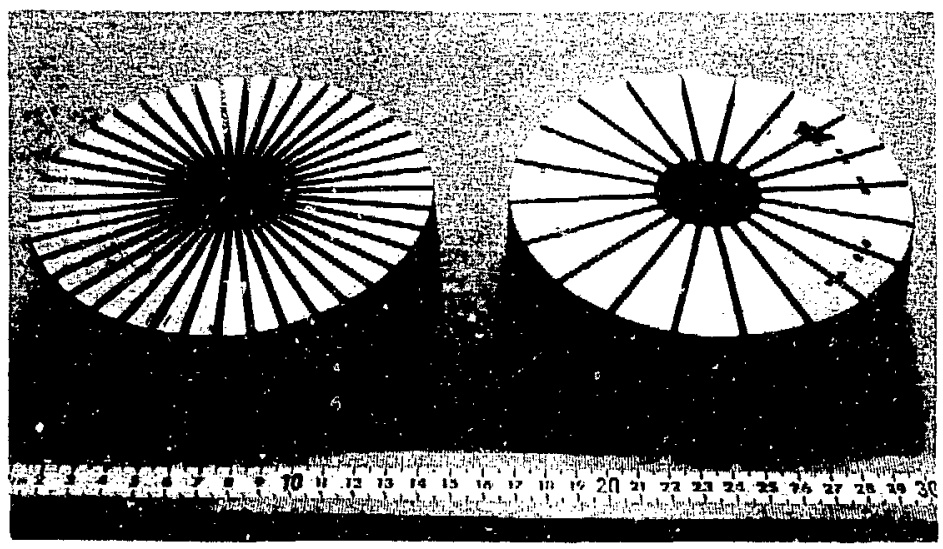

Fig. 3. Two kinds of cylinders for supporting fuel plates in canisters. 
COMPLETE SYSTEM

DETECTOR BODY

Design
Figure 4 shows the complete measurement system used with a birdcage. Standard coincidence electronics are used. ${ }^{l}$ The preamplifiers are mounted in tile high-voltage (hv) junction box at the top of the detector to minimize the number of cables connected to the detector; only one hv cable and one preamplifier cable are required. The detector is lowered into the birdcage by hand using the handle just visible at the top of the detector in Fig. 4.

Because che canister is permanently mounted in the birdcage, the neutron detector must either surround the entire birdcage or fit inside the

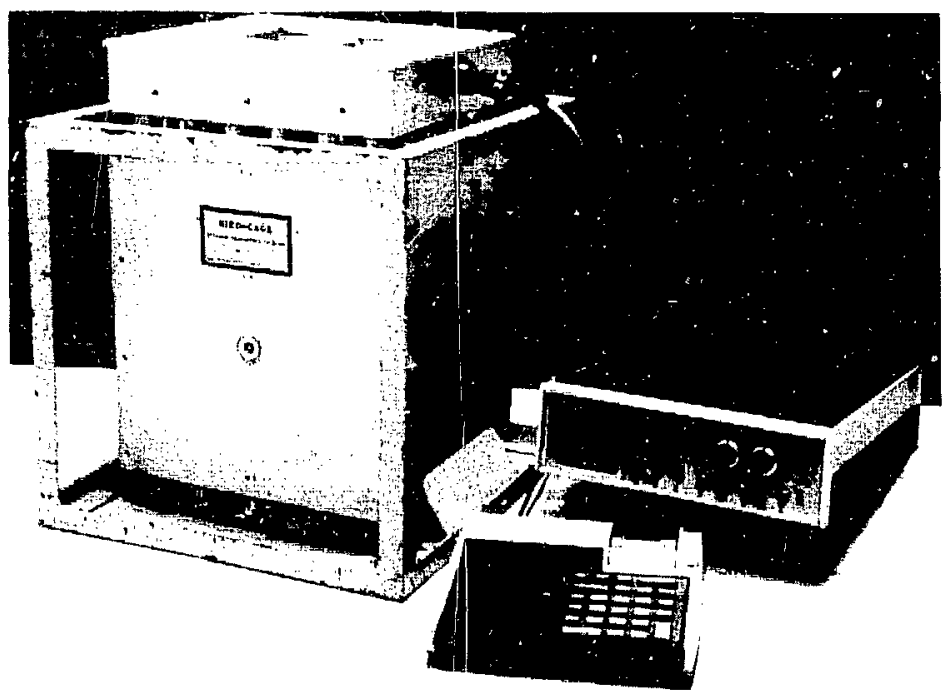

Fig. 4. The complete measurement system. The detector is in its normal measuring position inside the birdcage. 
Design

(cont)

3 He Counter Tubes and Cadmiun birdcage and around the canister; the latter approach was selected because of size, cost, and convenience of operating the detector.

The detector body consists of $20{ }^{3} \mathrm{He}$ proportional counter tubes embedded in polyethylene. Thin cadmium layers $(0.04 \mathrm{~cm}$ thick) outside and inside the detector reduce room background interference and prevent neutrons thermalized in the detector's polyethylene from traveling to the canister and inducing fissions in the plutonium fuel plates. The cadmium is covered with anodized aluminum.

Uniformity of Efficiency
The bracket that supports the canister in the birdcage and the plumbing below the bracket make it difficult to design a detector that has uniform efficiency throughout the canister. The best uniformity was obtained by constructing a rectangular rather than circular detector and by extending two sides of the detector as far down into the birdcage as allowed by the plumbing. Top- and side-view schematics of the detector are shown in Figs. 5 and 6 , respectively. A schematic of the detector in the birdcage is shown in Fig. 7 , and a photograph of the detector alone is shown in Fig. 8.

The two short sides of the detector are slanted at the bottom to match the slope of the canister support bracket in the birdcage. When the detector is lowered into the birdc: ge, it rests on the canister support bracket. The two short sides of the detector are thicker than the two long sides 


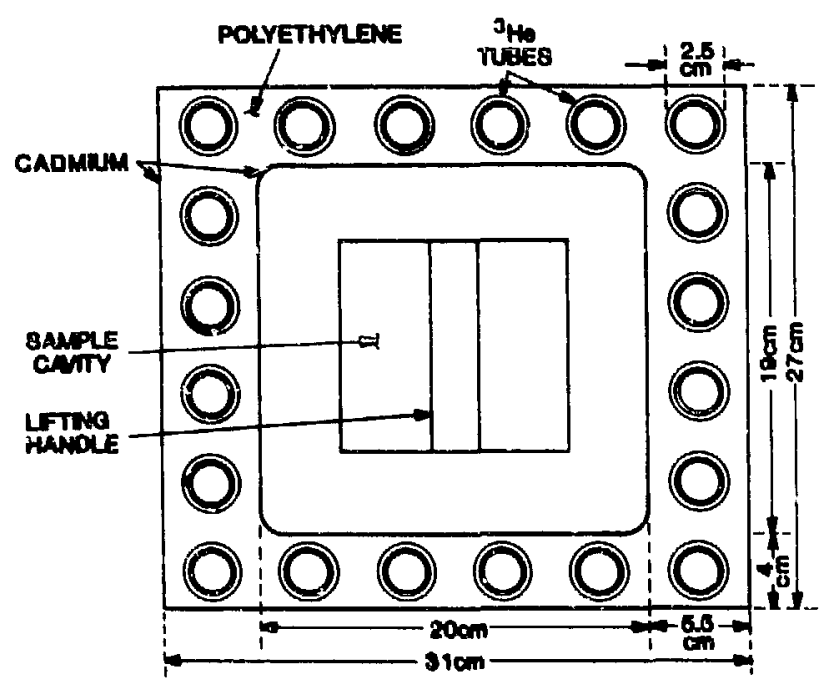

Fig. 5. Schematic of the birdcage detector (top view).

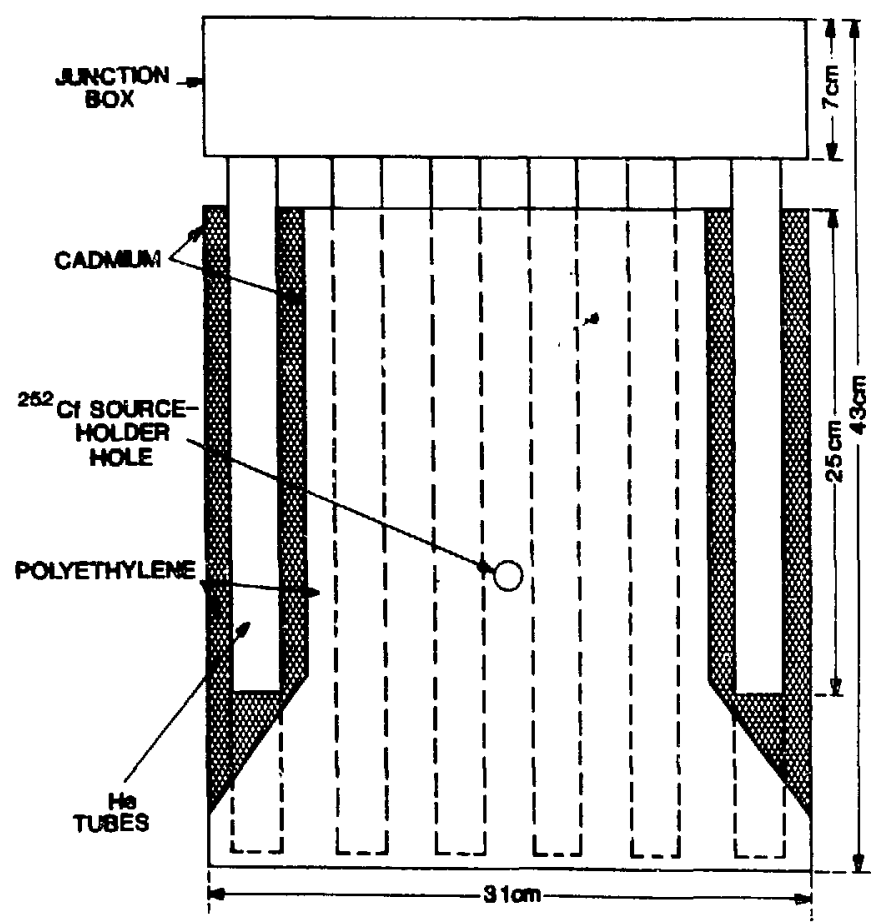

Fig. 6. Schematic of the birdcage detector (side view). 


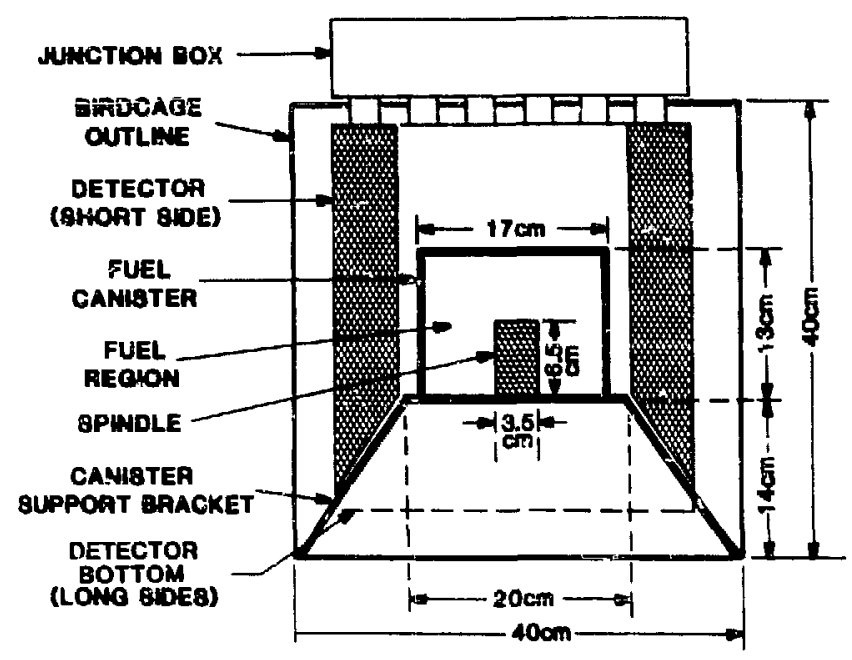

Fig. 7. Schematic of the detector in the birdcage (side view).

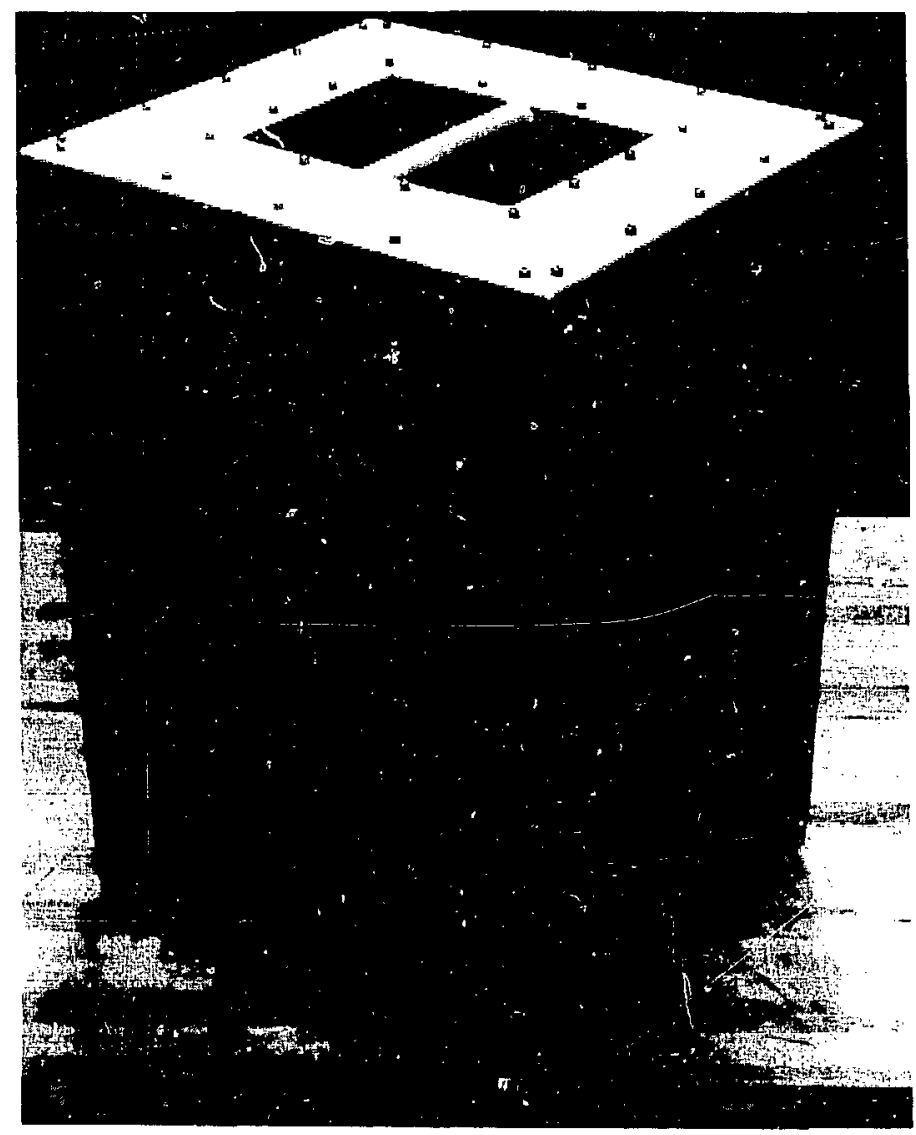

Fig, 8. The birdcage detector. 
Uniformity of

Efficiency

(cont)

${ }^{252}$ Cf Source Holder

DETECTOR TUBES

HIGH-VOLTAGE JUNCTION BOX to com $_{1}$ ensate for their shorter length and thus

to improve the uniformity of the efficiency.

The uniformity can be further improved by placing polyethylene (1) across the top of the detector under the handle and (2) under the canister support bracket and around the plumbing fixtures. However, it was decided for operational convenience not to include these extra pieces; the lower pieces are a nuisance, and the upper piece blocks the view of the canister and bracket.

A threaded hole in one side of the detector is used to support a ${ }^{252} \mathrm{Cf}$ normalization source holder (see the heading ${ }^{252}$ Cf Normalization Source in this section).

A11 20 detector tubes are $2.54-\mathrm{cm}-\mathrm{diam}{ }^{3} \mathrm{He}$ proportional counters. The ${ }^{3}$ He pressure is $4 \mathrm{~atm}$, and the quench gas is an argon-methane mixture. The 12 tubes on the detector's long sides have $28 \mathrm{~cm}$ of active length. The 8 tubes on the short sides have $22 \mathrm{~cm}$ of active length. Reuter-Stokes, Inc., manufactured the tubes; the long tubes are designated RS-P4-0811-101, and the short ones are designated RS-P4-0808-103.

Figure 9 shows the hv junction box with the cover removed. The hiv and preamplifier power leads are filtered as they enter the junction box to improve 


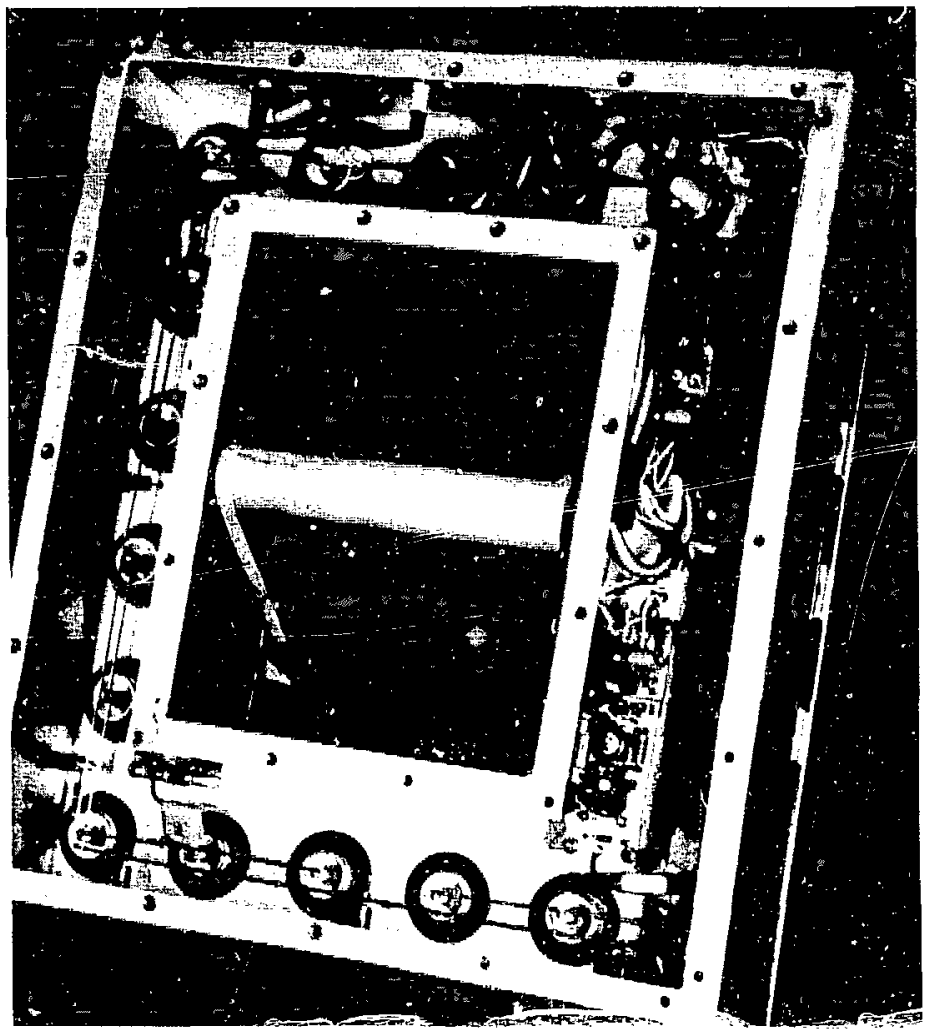

Fig. 9. The hv junction box with the cover removed.

HIGH-VOLTAGE JUNCTION B.OX (cont) the noise immunity. The four preamplifiers are identical to those used in the high-level neutron coincidence counter (KLNCC). 1 Three long tubes and two short tubes are connected to each preamplifier. Capsules of silica-gel desiccant are mounted under the cover of the hy junction box to prevent hv breakdown from moisture.

The coincidence electronics package is the standard unit used with the HLNC.C. 1
COIACIDEHCE ELECTROAICS PACKAGE 


\section{Recomended Settings}

The recommended settings for use with the birdcage counter are

\author{
$\mathrm{hv}=1500 \mathrm{~V}$ \\ Discriminator $=1.5 \mathrm{~V}$ \\ Gate width $=32 \mu \mathrm{s}$ \\ Predelay $=4.5 \mu \mathrm{s}$ (standard internal \\ setting).
}

The preamplifier cable is wired to use channels $1,2,3$, and 4; channels 5 and 6 are not used.

${ }^{252}$ CF NGRALIIZATION SOURCE
A ${ }^{252}$ Cf normalization source is included with the system so that future measurements can be normalized to calibration data. A photugraph of the ${ }^{252} \mathrm{Cr}$ source screwed onto its source holder is shown in Fig. 10. A bottom view of the birdcage counter showing the ${ }^{252} \mathrm{Cf}$ source in its standard measuring position is shown in Fig. 11 . Because the counter has no bottom reflector, the ${ }^{252}$ Cf source counting rate depends on the location of the counter. Thus the reference counting rate measured at the time of calibration must be given with the measurement conditions snecified; usually this will be with the counter upright, resting on a concrete floor, at least $1 \mathrm{~m}$ from concrete walls. 


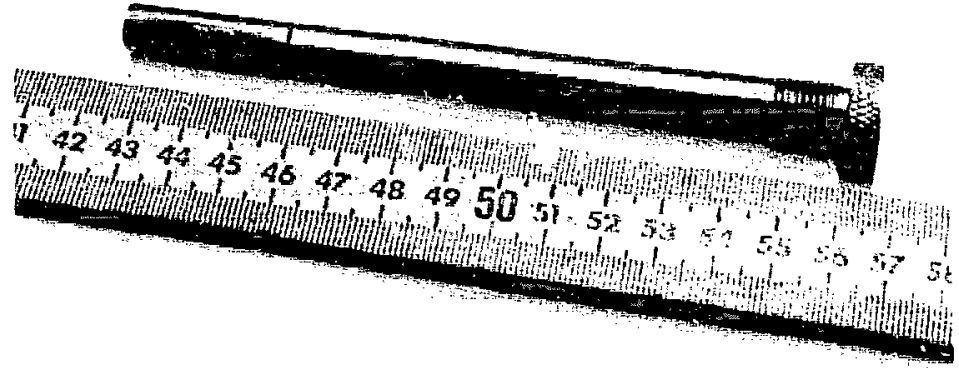

Fig. 10. The ${ }^{252} \mathrm{Cf}$ source and source holder.

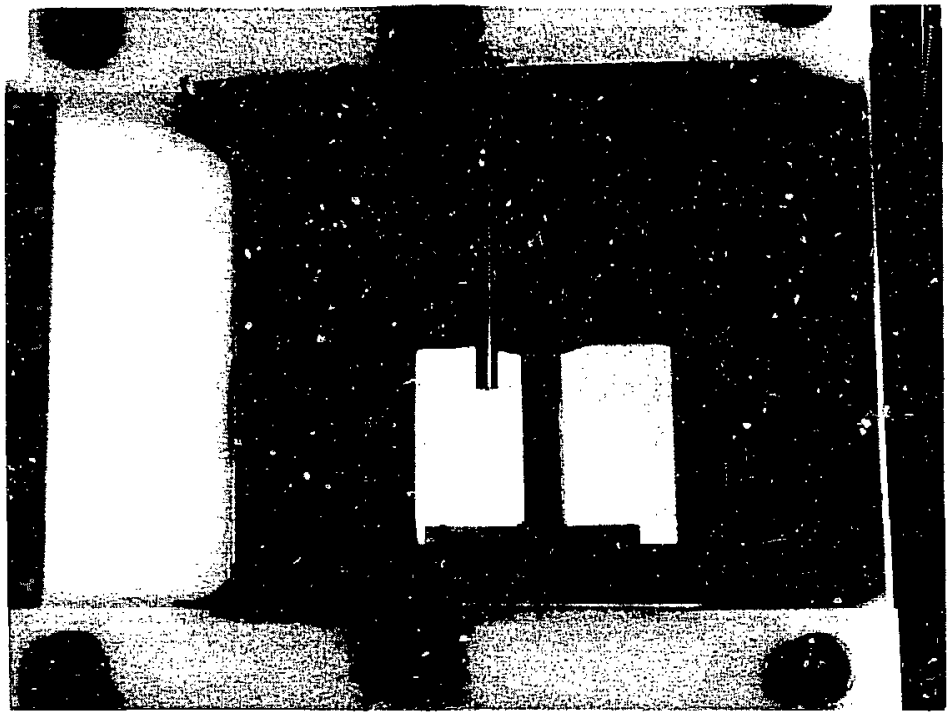

Fig. 11. Bottom view of the birdcage detector showing the $252 \mathrm{Cf}$ source in its standard measuring position. 


\section{DETECTION EFFICIENCY}

\section{DIE-AYAY TIME}

DEADTIME COEFFICIENTS
The absolute neutron detection efficiency was determined using a calibrated ${ }^{252} \mathrm{Cf}$ source mounted on the standard source holder and screwed into the birdcage counter through the source-holder hole. The detector was resting on a concrete floor $\sim 2 \mathrm{~m}$ from the nearest wa11. With the electronics set up as described previously (see Recommended Settings under Coincidence Electronics Package in the Measurement System), the efficiency obtained from this measurement was $4.9 \%$.

The average neutron lifetime or detector die-aviay time $\tau$ was determined by measuring the ${ }^{252} \mathrm{Cf}$ coiricidence rate with $16-, 32-$, and $64-\mu$ s gate widths. The die-away time inferred from these measurements was $\tau=30 \mu \mathrm{s}$.

The coincidence deadtime coefficient $\delta$ is defined by the following deadtime-correction equation:

$$
R=R_{m} e^{\delta T_{m}}
$$

where

$$
\begin{aligned}
& R_{m}=\text { measured coincidence rate, } \\
& R=\text { true coincidence rate, and } \\
& T_{m}=\text { measured totals rate. }
\end{aligned}
$$


DEADTINE COEFFICIEHTS (cont)
The recommended value of $\delta$ for the 4-channel

birdcage counter is $\delta=2.84+2.72 \times 10^{-6} \mathrm{x}$

$T_{m} \mu s$. The totals deadtime coefficient, $\Delta=\delta / 4$, is defined by

$$
T=T_{m} e^{\Delta T_{m}},
$$

where $T$ is the true totals rate.

STABILITY

ANGULAR RESPOMSE

A thin plutonium fuel plate $(5 \mathrm{~cm}$ wide by $5 \mathrm{~cm}$ high) was placed in one of the slots in a cylindrical fuel holder in the birdcage canister (see Fig. 2). The plate was measured with the birdcage counter for angular positions from $0^{\circ}$ to $90^{\circ} 10^{\circ}$ is parallel to the handle of the birdcage counter). The normalized efficiency, plotted in Fig. 12, is uniform within $\pm 2 \%$.

VERTICAL RESPONSE

A thin plutonium fuel plate $15 \mathrm{~cm}$ wide by $2.5 \mathrm{~cm}$ high) was measured in the fuel canister at $0^{\circ}$ and at four vertical positions--each $2.5 \mathrm{~cm}$ higher than the previous one--starting at the bottom of 


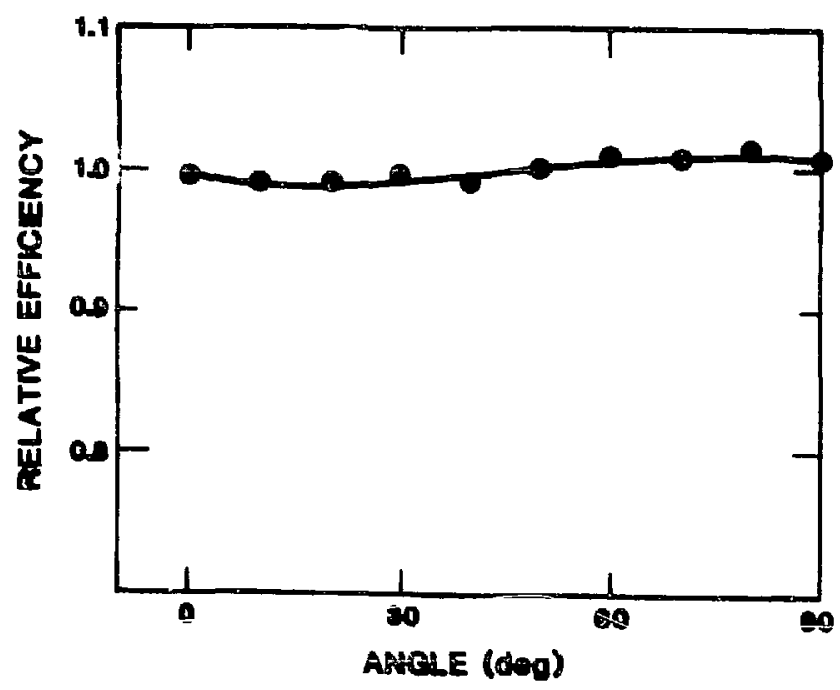

Fig. 12. Plot of relative detector efficiency vs angle. Measurements were made with a fuel plate. Zero degrees corresponds to the plate being parallel to the lifting handle.

VERTICAL RESPONSE

(cont) the canister. The nurmalized efficiency is plotted in Fig. 13. The relative efficiency varies from $97 \%$ at the botton to $102 \%$ at the second highest position. The efficiency falloff at high and low positions is causcd by the lack of top and bottom reflectors and by the short tubes on the sloped sides of the detector.

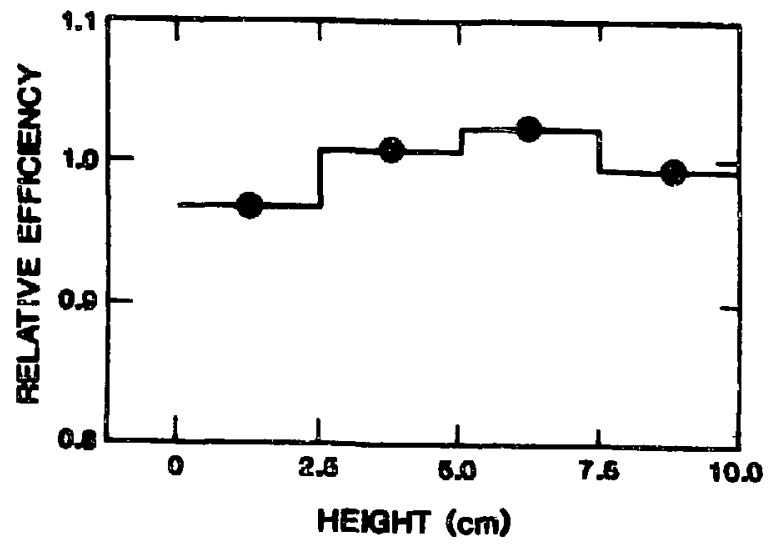

Fig. 13. Plot of relative detector efficiency vs height. Measurements were made with a fuel plate in four vertical positions--each $2.5 \mathrm{~cm}$ higher than the previous one--starting at the bottom of the canister. 
BIRDCAGE POSITIONING

MULTIPLICATION CORRECTION
Because there is no bottom reflector in the birdcage counter, calibrations and assays should ie performed with the birdcage resting on the same material--a concrete floor or a block of polyethylene, for example.

Mectron multiplication will be significant when large quantities of plutonium are stored in one birdcage canister. Unless thie canisters are full, the multiplication will also vary with the positions of the plates in the canisters. Therefore, if the ratio of $(\alpha, n)$ to spontaneous fission neutrons can be measured or calculated for the type of fuel plates being measured, then a multiplication correction is recommended to reduce the scatter in the assay results that is due to varying multiplication. The muitiplication-correction procedure ${ }^{2}$ used in the coincidence counting calibration program CAL4 ${ }^{3}$ for the HP-85 computer is recommended for this type of material. 


\section{REFERENCES}

1. J. E. Swansen, P. R. Collinsworth, and M. S. Krick, "Shift-Register Coincidence Electronics System for Thermal Neutron Counters," Nucl. Instr. \& Methods 176, 555 (1980).

2. N. Ensslin, "A Simple Self-Multiplication Correction for In-Plant Use," Los Alamos National Laboratory document LA-UR-84-3285.

3. M. S. Krick, "HP-85 Calibration Software for Thermal Neutron Coincidence Counters (Program CAL4)," Los Alamos National Laboratory document Q-1-85-44. 